\title{
Expression analysis of genes associated with human osteosarcoma tumors shows correlation of RUNX2 overexpression with poor response to chemotherapy
}

\author{
Bekim Sadikovic1,2, Paul Thorner'1, Susan Chilton-MacNeill', Jeff W Martin ${ }^{4}$, Nilva K Cervigne ${ }^{3}$, Jeremy Squire*4 and \\ Maria Zielenska1,2
}

\begin{abstract}
Background: Human osteosarcoma is the most common pediatric bone tumor. There is limited understanding of the molecular mechanisms underlying osteosarcoma oncogenesis, and a lack of good diagnostic as well as prognostic clinical markers for this disease. Recent discoveries have highlighted a potential role of a number of genes including: RECQL4, DOCK5, SPP1, RUNX2, RB1, CDKN1A, P53, IBSP, LSAMP, MYC, TNFRSF1B, BMP2, HISTH2BE, FOS, CCNB1, and CDC5L.

Methods: Our objective was to assess relative expression levels of these 16 genes as potential biomarkers of osteosarcoma oncogenesis and chemotherapy response in human tumors. We performed quantitative expression analysis in a panel of 22 human osteosarcoma tumors with differential response to chemotherapy, and 5 normal human osteoblasts.

Results: RECQL4, SPP1, RUNX2, and IBSP were significantly overexpressed, and DOCK5, CDKN1A, RB1, P53, and LSAMP showed significant loss of expression relative to normal osteoblasts. In addition to being overexpressed in osteosarcoma tumor samples relative to normal osteoblasts, RUNX2 was the only gene of the 16 to show significant overexpression in tumors that had a poor response to chemotherapy relative to good responders.

Conclusion: These data underscore the loss of tumor suppressive pathways and activation of specific oncogenic mechanisms associated with osteosarcoma oncogenesis, while drawing attention to the role of RUNX2 expression as a potential biomarker of chemotherapy failure in osteosarcoma.
\end{abstract}

\section{Background}

Osteosarcoma is the most common pediatric tumor of the bone. Clinically, osteosarcoma has a bimodal distribution, with the majority of patients developing the disease during the period of active bone growth in early adolescence. The treatment generally involves surgery, often involving a loss of limb, and adjuvant chemotherapy. The best prognostic marker for osteosarcoma is the response to chemotherapy, where good response to chemotherapy is associated with an overall more favorable patient outcome and survival $[1,2]$.

* Correspondence: squire@queensu.ca

4 Department of Pathology and Molecular Medicine, Richardson Labs, Queen's University, Kingston, K7L 3N6 Canada

Full list of author information is available at the end of the article
At the molecular level osteosarcoma is characterized by a high level of genomic instability, highly heterogenous karyotypes both intra- and inter-tumor, and gross changes in gene expression [3-9]. Human osteosarcoma tumors often have osteoblast-like features but may vary within a broad range of epithelial mesenchymal lineages reflective of their poorly differentiated phenotype [1012]. Therefore, assessment of the molecular changes in osteosarcoma tumors relative to normal osteoblasts can provide important insights concerning gene expression changes associated with both osteosarcoma oncogenesis and with molecular alterations governing differential clinical response to treatment.

The genetic change most commonly associated with osteosarcoma is the loss of the TP53 tumor suppressor 
gene through either genetic mutation or loss of gene expression [13-15]. Patients with Li-Fraumeni syndrome, which results from loss of TP53, have a strong predisposition to developing osteosarcoma [16]. Another tumor suppressor gene whose loss of expression is linked to osteosarcoma is $R B 1$ [17]. In our recent studies, we have also shown that these genes play a central role in osteosarcoma-related gene expression networks both in human osteosarcoma cell lines [18] and tumor tissues [19]. We used a unique bioinformatic integrative wholegenome approach to map the genetic and epigenetic changes in osteosarcoma tumors and to identify gene networks related to osteosarcoma oncogenesis. Changes that showed the most significant associations with osteosarcoma gene networks included: overexpression and the most significant copy number gain of the chromosome 6p21.1 RUNX2 locus, loss of expression and genomic loss of the DOCK5 and TNFRSF10A loci at chromosome 8p21.1-21.3, and hypomethylation, copy number gain, and overexpression of the HISTH2BE gene at chromosome 1q21. Other genes that showed deregulated expression and significant contribution to osteosarcoma gene networks included overexpressed SPP1, IBSP, BMP2, and $c-M Y C$, and uderexpressed CDKN1A, LSAMP, and $C C N B 1$. Another gene that is thought to play a role in osteosarcoma and has been shown to be overexpressed is the FOS proto-oncogene [20,21]. Similarly, $C D C 5 L$ has been recently proposed as the putative oncogene at the 6 221 locus in osteosarcoma [22]. Finally, a DNA repair gene, $R E C Q L 4$, has been shown to be overexpressed, and its level of overexpression correlates with overall genomic instability in osteosarcoma [23].

Microarray analysis and reverse-transcriptase polymerase chain reaction (RT-PCR) are useful for the molecular classification of tumors and for deriving biological mechanisms that underpin differential prognosis for patients with various types of cancer, including osteosarcoma [24-27]. The use of gene-expression profiling in clinical practice is however limited by the large number of genes that need to be analyzed and by the lack of reproducibility of various array platforms and interpretative methods [28]. Quantitative RT-PCR methods can be readily applied to RNA derived from formalin-fixed, paraffin-embedded (FFPE) pathological specimens, are reproducible and may be highly applicable in clinical practice [29], particularly for a rare tumor such as osteosarcoma in which access to frozen tissue is often limited. RT-PCR can only typically be used to analyze a small number of genes. Therefore it is important to select gene subsets for detailed analyses in which multiple lines of evidence implicate clinical utility. In previous studies, we $[18,19]$, and others $[22,30,31]$ have performed microarray analyses of osteosarcoma cell lines and tissue samples and identified a series of genes with strong potential as bio- markers with clinical utility. Thus, the objective of the current study was to examine expression profiles of RECQL4, DOCK5, SPP1, RUNX2, RB1, CDKN1A, TP53, IBSP, LSAMP, MYC, TNFRSF1B, BMP2, HISTH2BE, $F O S, C C N B 1$, and $C D C 5 L$ genes in a cohort of osteosarcoma tumors and normal human osteoblasts. As a result, we show that RECQL4, SPP1, RUNX2, and IBSP are significantly overexpressed, and DOCK5, CDKN1A, RB1, $P 53$, and LSAMP show significant loss of expression relative to normal osteoblasts. We also show that $R U N X 2$ was the only gene with significant overexpression in tumors with an unfavorable response to chemotherapy relative to favorable responders.

\section{Methods}

\section{Tissue samples}

The collection of frozen tissue specimens $(n=15)$, archival formalin-fixed, paraffin-embedded osteosarcoma sections $(n=7)$, and clinicopathological data was obtained and handled in accordance with the Hospital for Sick Children Research Ethics guidelines (Toronto, Canada). This was a retrospective study of chemotherapy-naive biopsy samples collected sequentially between 1996 and 2005, and all specimens presented a tumor content higher than $90 \%$. All patients were subjected during treatment to standard regimens for osteosarcoma, comprising cisplatin, doxorubicin, and methotrexate. The patient tumor specimens were revised at the time of study by the pathologist (P.T.). The details of the cases are presented in Table 1. The Huvos grading system was used to rate the level of tumor necrosis following preoperative chemotherapy: Grade I, little or no effect of chemotherapy noted; Grade II, partial response to chemotherapy, with between $50 \%$ and $90 \%$ necrosis; Grade III, greater than $90 \%$ necrosis; and Grade IV, no viable tumor cells are apparent [32]. The good responders are patients with necrosis $\geq 90 \%$ [33]. Normal human osteoblasts that were isolated from surgical bone specimens from five healthy individuals were obtained from Promocell (Heidelberg, Germany).

\section{RNA isolation}

Total RNA from snap-frozen tissue (5 normal human osteoblasts and 15 tumors) was extracted and purified using the TRIzol Reagent method according to the manufactures protocol (Invitrogen, Carlsbad, CA, USA). FFPE tissues (7 tumors) were deparaffinized with xylene, washed with $\mathrm{ETOH}$, and digested with a proteinase $\mathrm{K}$ buffer [34]. Total RNA was extracted and purified as above with TRIzol reagent. The RNA quality was good for all samples as assessed by BioAnalyzer RNA 600 Nano Kit (Agilent Technologies, Palo Alto, CA). Additionally, the overall trends for expression in tumors relative to normal osteoblasts were similar in frozen and FFPE sam- 
Table 1: Descriptive and histopathological features of the tumor cohort and normal osteoblasts.

\begin{tabular}{|c|c|c|c|c|c|c|}
\hline Sample & Huvos grade & Group & Age & Sex & Site & Histology \\
\hline HOB A & NA & Normal & NA & $M$ & femur & $\begin{array}{c}\text { osteoblasts } \\
\text { normal }\end{array}$ \\
\hline HOB B & NA & Normal & NA & $M$ & femur & $\begin{array}{c}\text { osteoblasts } \\
\text { normal }\end{array}$ \\
\hline $\mathrm{HOBC}$ & NA & Normal & NA & $\mathrm{F}$ & femur & $\begin{array}{c}\text { osteoblasts } \\
\text { normal }\end{array}$ \\
\hline HOB D & NA & Normal & NA & $M$ & femur & $\begin{array}{c}\text { osteoblasts } \\
\text { normal }\end{array}$ \\
\hline HOBE & NA & Normal & NA & M & femur & $\begin{array}{c}\text { osteoblasts } \\
\text { normal }\end{array}$ \\
\hline 176 & III & Good & 7 & $M$ & humerus & chondroblastic \\
\hline 177 & III & Good & 10 & M & femur & chondroblastic \\
\hline 186 & III & Good & 7 & $\mathrm{~F}$ & humerus & osteoblastic \\
\hline 255 & III & Good & 9 & $M$ & tibia & osteoblastic \\
\hline 259 & III & Good & 7 & M & femur & osteoblastic \\
\hline 260 & III & Good & 14 & $\mathrm{~F}$ & femur & osteoblastic \\
\hline 214 & IV & Good & 4 & $\mathrm{~F}$ & femur & osteoblastic \\
\hline 217 & III & Good & 10 & $\mathrm{~F}$ & tibia & osteoblastic \\
\hline 220 & IV & Good & 12 & $M$ & tibia & fibroblastic \\
\hline 223 & III & Good & 12 & $\mathrm{~F}$ & humerus & osteoblastic \\
\hline 230 & III & Good & 12 & $\mathrm{~F}$ & fibula & osteoblastic \\
\hline 174 & $\|$ & Poor & 14 & $M$ & femur & osteoblastic \\
\hline 178 & I & Poor & 5 & $\mathrm{~F}$ & humerus & osteoblastic \\
\hline 179 & 1 & Poor & 11 & $\mathrm{~F}$ & tibia & osteoblastic \\
\hline 182 & I & Poor & 13 & $M$ & femur & osteoblastic \\
\hline 183 & II & Poor & 12 & $\mathrm{~F}$ & femur & poorly differ. \\
\hline 187 & I & Poor & 6 & $\mathrm{~F}$ & femur & osteoblastic \\
\hline 234 & $\|$ & Poor & 13 & $M$ & femur & osteoblastic \\
\hline 254 & 1 & Poor & 7 & M & humerus & osteoblastic \\
\hline 256 & I & Poor & 15 & $M$ & femur & poorly differ. \\
\hline 261 & I & Poor & 13 & $M$ & femur & osteoblastic \\
\hline 211 & I & Poor & 12 & $\mathrm{~F}$ & femur & osteoblastic \\
\hline
\end{tabular}

ples corroborating the quality of the extracted RNA (Additional file 1).

\section{Quantification of mRNA Expression}

Quantitative real-time PCR (qRT-PCR) was used to quantify mRNA expression levels of 16 genes (RUNX2, DOCK5, TNFRS1B, HISTH2BE, P21, SSP1, P53, IBSP, CCNB1, BMP2, LSAMP, RB1, FOS, MYC, RECQL4, and $C D C 5 L$ ). Briefly, 1-2 ug of total RNA was converted to cDNA using GeneAmp Gold RNA PCR Core Kit (Applied Biosystems, Foster City, CA, USA), as per man- ufacturers recommendations. Primers were designed to specifically amplify templates of approximately 90-130 nucleotides overlapping exon boundaries of 3 ' terminal exons using the Primer-Blast software http:// www.ncbi.nlm.nih.gov/tools/primer-blast/. The primers were subsequently tested by both PCR and qRT-PCR for specificity and single band amplification. The sequences of the PCR primer pairs used for each gene are shown in Additional file 2. The qRT-PCR assays for a particular gene were undertaken at the same time for all samples under identical conditions, in duplicate. The cycling con- 
ditions were as follows: $95^{\circ} \mathrm{C}$ for $2 \mathrm{~min}, 40$ cycles of $95^{\circ} \mathrm{C}$ for $15 \mathrm{sec}$ and $60^{\circ} \mathrm{C}$ for $45 \mathrm{sec}$, with a final extension $72^{\circ} \mathrm{C}$ for $5 \mathrm{~min}$.

The mRNA expression levels were determined using Platinum SYBR Green qPCR Supermix-UDG with Rox (Invitrogen, Carlsbad, CA, USA), and the Applied Biosystems Prism 7900 Sequence Detection System (PE Applied Biosystems, Inc., Foster City, CA). The relative expression level of the genes of interest was computed relative to the endogenous control, phosphoglycerate kinase (PGK), to normalize for variances in the quality of RNA and the amount of input cDNA. Additionally, we validated our experimental conditions by analyzing the expression of two genes identified in our previous microarray study [19]; $A 2 M$, the highest overexpressing gene of the set and our positive control for the current study; and SLC14A, the gene with the lowest expression of the set and our negative control for the current study (Additional file 3). The mRNA expression levels for each sample were determined as fold-change values relative to the mean baseline expression levels for five human osteoblasts (HOBs), using the delta delta Ct method of analysis [35].

\section{Statistical analysis}

Results of the delta-delta Ct analysis were $\log _{10}$ transformed and imported to Partek Genomic Suite software (Additional file 1). The tumor samples were grouped by Huvos grade into those with favorable response to chemotherapy (Grades I and II) and unfavorable response (Grades III and IV); and were compared either as a group to normal human osteoblasts (i.e. tumor vs. normal), or to each other (i.e. unfavorable vs. favorable). Differences in p-values between groups were obtained using the nonparametric rank-sum Mann-Whitney test, and fold change differences between groups were obtained using the 1-way ANOVA tool (Additional file 4) using the Partek Genomic Suite software. This study was designed as a confirmatory analysis based on specific genes that were previously shown to have significant expression changes in steosarcoma, and thus multiple test correction was not applicable [36]. This analysis is designed to assess the correlation of specific gene expression as an individual parameter against the ostosarcoma phenotype, and is not meant to assess these genes as a group, gene network, or a multiple gene signature.

\section{Results}

The pathology of 22 osteogenic sarcomas and follow-up biopsies were analysed to determine response to chemotherapy and percent of necrotic tissue. This allowed tumors to be grouped as good responders (Huvos grades III and IV with favorable responses to chemotherapy) and poor responders (Huvos grades I and II with unfavorable responses to chemotherapy) (Table 1). Eleven tumors were identified to have $95 \%$ or more necrosis as a result of chemotherapy and were labelled as favorable responders, and the remaining 11 tumors were characterized as unfavorable responders. The baseline control consisted of a panel of five normal human osteoblast samples. The majority of tumors displayed osteoblastic histology, and most tumors and all osteoblast controls were of femoral origin.

In order to quantitatively assess the expression of the target genes (RECQL4, DOCK5, SPP1, RUNX2, RB1, CDKN1A, TP53, IBSP, LSAMP, MYC, TNFRSF1B, $B M P 2$, HISTH2BE, FOS, CCNB1, and CDC5L) we performed qRT-PCR on the tumor cohort and human osteoblast samples (Additional file 1). Statistical analysis of these data revealed significant changes in a number of genes (Table 2). Tumors displayed significant overexpression of RECQL4, SPP1, RUNX2, and IBSP genes and loss of expression of DOCK5, CDKN1A, RB1, TP53, and $\operatorname{LSAMP}(\mathrm{p}<0.05)$ (Figure 1). The highest level of overexpression was measured in SPP 1 with 113-fold overexpression, while the largest reduction of expression of 36 -fold was evident in the DOCK5 gene. Comparison of tumors with unfavorable response to ch emotherapy to favorable responders revealed $R U N X 2$ as the only significant gene $(\mathrm{p}=0.03)$. On average unfavorable responders to chemotherapy showed 3.3-fold increase in the RUNX2 gene expression relative to favorable responders. Furthermore, RUNX2 expression showed a trend towards overexpression going from normal osteoblasts to favorable responders to chemotherapy and then to unfavorable responders to chemotherapy (Figure 1). The tumor sample \#256 that exhibited the worst response to chemotherapy, also showed highest levels (113-fold) of RUNX2 overexpression (Additional file 1).

The remaining genes showed no significant changes in expression in tumors relative to normal osteoblasts. MYC, BMP2, and FOS show an associative trend when overexpressed, and TNFRSF10A shows a trend in underexpression in the tumor cohort. Notably, CDC5L showed essentially no change in expression levels relative to normal osteoblasts.

\section{Discussion}

Transformation of normal cells and initiation of tumorigenesis involves a combination of genetic and epigenetic changes [37]. Progressive acquisition of such changes ultimately results in destabilization of the genome, deregulation of gene expression pathways and activation of oncogenic gene expression networks. Identification of key genes, or network "nodes", will provide a more comprehensive understanding of tumorigenic processes, and provide more effective diagnostic, prognostic and therapeutic markers. In our recent integrative epi/genomic studies of osteosarcoma cell lines [18] and tumor 
Table 2: Statistical evaluation of the tumor-specific and chemotherapy response-related gene expression signatures.

\begin{tabular}{|c|c|c|c|c|c|}
\hline \multirow[t]{2}{*}{ Gene } & \multicolumn{2}{|c|}{ Tumor vs. Normal } & \multicolumn{2}{|c|}{ Poor vs Good } & \multirow[t]{2}{*}{ References } \\
\hline & $p$-value & fold change & p-value & fold change & \\
\hline RECQL4 & 0.00087 & 10.16 & 0.84739 & -1.14 & {$[22]^{*}$} \\
\hline DOCK5 & 0.00094 & -36.81 & 0.86960 & -1.58 & [18] \\
\hline SPP1 & 0.00180 & 113.97 & 0.57674 & -1.21 & [18] \\
\hline RUNX2 & 0.00222 & 7.13 & 0.02782 & 3.30 & [18] \\
\hline RB1 & 0.00252 & -14.87 & 0.14164 & 5.14 & [16] \\
\hline CDKN1A & 0.00409 & -8.61 & 0.71798 & 1.27 & [18] \\
\hline P53 & 0.00409 & -20.63 & 0.45016 & 1.65 & [12-15] \\
\hline IBSP & 0.03382 & 9.61 & 0.45016 & -1.25 & [18] \\
\hline LSAMP & 0.04278 & -11.56 & 0.14164 & 4.42 & [18] \\
\hline MYC & 0.05492 & 3.05 & 0.56370 & 1.61 & [17] \\
\hline TNFRSF10A & 0.07359 & -2.34 & 1.00000 & -1.07 & [18] \\
\hline BMP2 & 0.10975 & 3.86 & 0.36911 & 2.21 & [18] \\
\hline HISTH2BE & 0.26121 & 1.30 & 0.97381 & 1.10 & {$[18]$} \\
\hline FOS & 0.33725 & 2.34 & 0.56763 & 2.95 & {$[19,20]$} \\
\hline CCNB1 & 0.41368 & -1.20 & 0.46243 & -1.03 & [18] \\
\hline CDC5L & 0.90645 & -1.13 & 0.63043 & -1.98 & [21] \\
\hline
\end{tabular}

*References are to the original papers describing the change in expression in these genes in osteosarcoma

genomes [19] we identified a number of such genes. A survey of the current literature allowed us to augment this list to a total of sixteen genes whose expression levels were assessed in an expanded tumor cohort. By comparing the gene expression levels to a panel of normal human osteoblasts, it allowed us to identify changes that are likely to be involved in osteosarcoma tumorigenesis. As a result, we identified significant disruptions of gene expression in nine of these genes, including loss of expression of DOCK5, CDKN1A, RB1, TP53, and LSAMP genes, and overexpression of RECQL4, SPP1, RUNX2, and IBSP genes.

Our study demonstrates a significant deregulation of proteins in osteosarcoma that are important effectors in the cell cycle and in differentiation. Significantly, we detected loss of TP53 expression, which may also play a role in loss of expression of $C D K N 1 A$, which encodes the cyclin-dependent kinase inhibitor 1A (p21) and whose expression is activated by p53 [38]. Loss of DOCK5 may play a similar role as it was shown recently that DOCK 5 expression is essential for bone differentiation, from precursor osteoclasts [39]. Interestingly, in our recent study we showed that DOCK5 is located in the most significant region of copy number loss in osteosarcoma $8 \mathrm{p} 21.2$-p21.3 [19] along with the TNFRSF10A gene, for which we see an overall trend of loss of expression in our current study. TNFRSF10A is a receptor activated by tumor necrosis factor-related apoptosis inducing ligand TNFSF10 (also known as TRAIL), and is involved in the transduction of cell death signal and induction of cell apoptosis, which is mostly independent of p53 signalling [40].

A significant region of copy number loss at 3q13.31 has been identified in our previous study [19], and has also been observed by another group in $56 \%$ of osteosarcomas. This region of copy number loss was shown to correlate with loss of expression and hypermethylation of the LSAMP gene, and the authors proposed LSAMP as a novel tumor suppressor in osteosarcoma [31]. Our data agree with these findings and show significant loss of expression of $L S A M P$ in the majority of our osteosarcoma samples. LSAMP codes for a neuronal surface glycoprotein found in cortical and subcortical regions of the limbic system, but it is currently unclear how this gene may be related to osteosarcoma tumorigenesis.

RUNX2 was one of the genes overexpressed in our set of tissue samples, and the only gene whose overexpression was significantly related to poor response to chemotherapy in osteosarcomas. RUNX2 is a member of the Runx transcription factor family consisting of RUNX1, RUNX2, and RUNX3 which function in the development of a number of tissues [41]. Of the three proteins, both RUNX1 and RUNX2 have been associated with oncogenesis. RUNX1 and RUNX2 upregulate LGALS3 (galectin3) [42], a protein which suppresses anoikis and drug- 

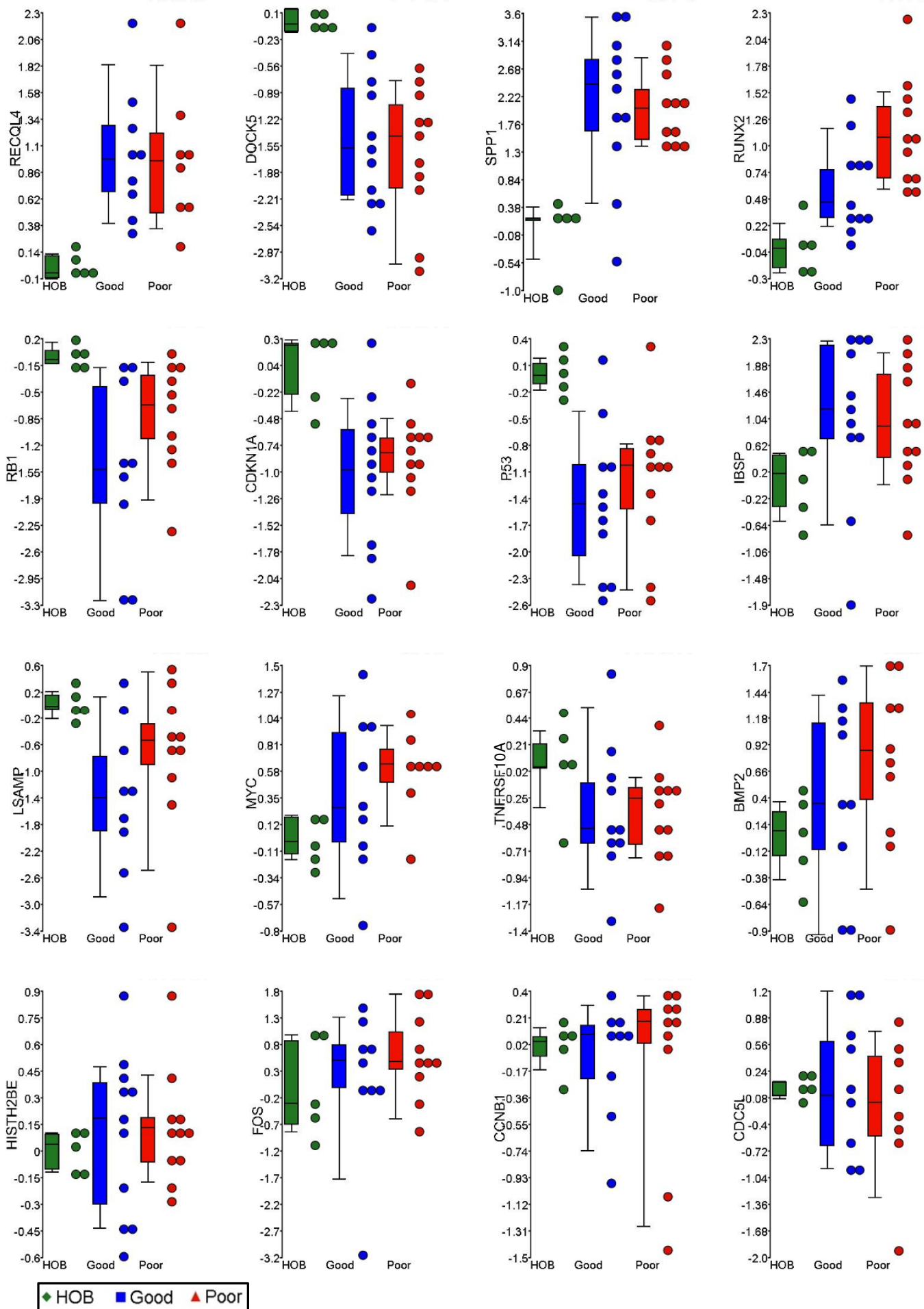

Figure 1 Expression analysis of osteosarcoma-related genes. qRT-PCR levels of gene expression of 16 osteosarcoma-related genes in 5 normal human osteoblasts and 22 human osteosarcoma samples are shown on $y$-axis. The samples are grouped based on the response to chemotherapy status on $y$-axis. Corresponding box and whiskers plots representing the mean, $25^{\text {th }}$ and $75^{\text {th }}$ percentile (boxes), and $10^{\text {th }}$ and $90^{\text {th }}$ percentile (whiskers) are also shown. From left to right, and top to bottom of the panel, the plots are placed in the order of Mann-Whitney p-value significance (tumor vs. normal). HOB: normal human osteoblasts; Good: Favorable response to chemotherapy (Huvos grades III and IV); Poor: Unfavorable response to chemotherapy (Huvos grades I and II). 
induced apoptosis [43] and whose expression is correlated with metastasis in osteosarcoma [44] and progression in glioma [45]. Similarly, in lymphoma, overexpression of RUNX2 and MYC results in the "collaboration" of the two corresponding proteins to attenuate apoptosis and promote proliferation [46]. In developing osteoblasts, expression of RUNX2 normally decreases during maturation [47], and overexpression of the gene leads to a higher rate of bone turnover [48]. In bone metastatic breast cancer, RUNX2 promotes cancer cell survival and growth by activating expression of $I H H$ and interacts with the TGF $\beta / B M P$ signal transduction pathway to parathyroid hormone-related protein (PTHrP) [49]. Thus the finding of elevated expression of RUNX2 in osteosarcomas with an unfavorable chemotherapy response is consistent with its oncogenic potential noted in other studies

In addition to $R U N X 2$, three other genes, SPP1, RECQL4, and IBSP showed significant overexpression. SPP1 (osteopontin), like RUNX2, is a member of the BMP-signalling protein family. It shows the highest overexpression (113-fold) in our analysis, and has previously been shown to be significantly overexpressed in osteosarcoma tumors [50] and cell lines [51]. Antisense knockdown of SPP1 RNA in osteosarcoma cells results in inhibition of in vivo tumorigenesis in mice. These findings suggest that overexpression of SPP1 plays a role in osteosarcoma tumorigenesis, in particular, in cells lacking expression of cell cycle regulators and differentiationrelated genes, as discussed earlier. RECQL4 is a gene whose protein product is involved in repair of DNA double stranded breaks and deregulation of its expression was recently shown to be strongly correlated with genomic instability in osteosarcoma [23]. Our data are consistent with this in further reaffirming the association of RECQL4 overexpression with osteosarcoma tumorigenesis. The final gene which showed significant overexpression in tumors relative to normal cells, IBSP, also known as bone sialoprotein, is a marker of terminal differentiation of bone. In normal osteoblasts RUNX2 and HDAC3 have been shown to suppress IBSP, and upon terminal differentiation loss, of RUNX2 expression derepresses IBSP and allows for terminal differentiation [52]. In tumors, however, although IBSP shows significant overexpression relative to osteoblasts, concurrent overexpression of RUNX2 indicates possible disruption of the terminal differentiation process.

By comparing our tumor panel, the majority of which $(17 / 22)$ are the osteoblastic histological subtype, we identified gene expression changes associated with osteosarcoma oncogenesis. However, a possible limitation of this study is that some of the genetic associations described may not be present in osteosarcoma lineages that arise from more primitive cells of origin, including mesenchymal precursors [53-55]. In addition to the associations of gene expression with oncogenesis, we showed that the $R U N X 2$ gene displays significant increase in expression in tumors with poor response to chemotherapy relative to the good responders. Our results may be reflective of either increased levels of gene expression in individual tumor cells during disease progression, or alternatively an increased proportion of cell lineages with RUNX2 expression in these genetically highly heterogenous cells. Both scenarios would allow selective advantage to the evolving cell lineages during tumorigenesis. Detailed immunohistochemical and imaging experiments will be required to further delineate these possibilities. It also remains to be determined if this correlation is evident at the protein level, and if so, RUNX2 may be a good histological marker for chemotherapy response, which is currently the best predictor of overall outcome in patients with osteosarcoma.

\section{Conclusion}

These data underscore the loss of tumor suppressive pathways the deregulation of cell cycle control proteins, and the activation of specific oncogenic mechanisms associated with osteosarcoma oncogenesis. Our results also draw attention to the role of $R U N X 2$ expression as a potential biomarker of chemotherapy failure in osteosarcoma.

\section{Additional material}

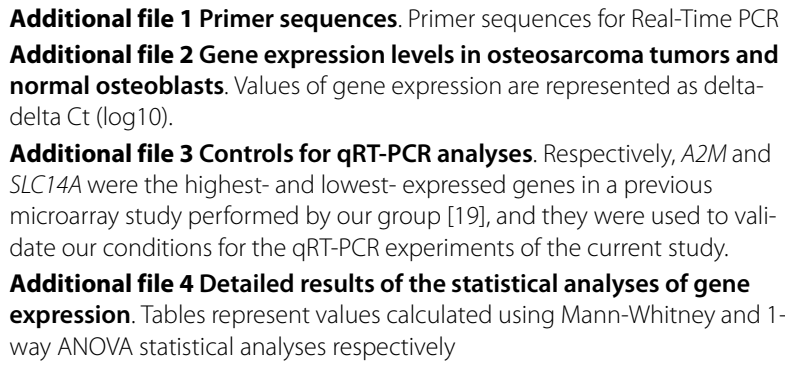

Additional file 1 Primer sequences. Primer sequences for Real-Time PCR Additional file 2 Gene expression levels in osteosarcoma tumors and normal osteoblasts. Values of gene expression are represented as deltadelta Ct (log10).

Additional file $\mathbf{3}$ Controls for qRT-PCR analyses. Respectively, A2M and SLC14A were the highest- and lowest- expressed genes in a previous microarray study performed by our group [19], and they were used to validate our conditions for the qRT-PCR experiments of the current study. Additional file 4 Detailed results of the statistical analyses of gene expression. Tables represent values calculated using Mann-Whitney and 1 way ANOVA statistical analyses respectively

Competing interests

The authors declare that they have no competing interests.

\section{Authors' contributions}

BS: Conceived and designed experiments, performed experiments, analysed data, drafted the manuscript. PT: Performed experiments. SCM: Performed experiments. JM: Revised the manuscript. NKC: Performed experiments, analysed data. JS: Conceived and designed experiments, revised the manuscript. $\mathrm{MZ}$ : Conceived and designed experiments, revised the manuscript. All authors have read and approved the final manuscript.

\section{Acknowledgements}

This work was supported by the Canadian Cancer Society/National Cancer Institute of Canada [grant \#016215]. B.S. is a Fellow of the National Cancer Institute of Canada (Terry Fox Foundation) and Restracomp Fellow at the Hospital for Sick Children, Toronto, Canada. 


\section{Author Details}

'Department of Pediatric Laboratory Medicine, Pathology Division, Hospital for Sick Children, Toronto, M5G 1 X8 Canada, ${ }^{2}$ Genetics and Genome Biology Program, Hospital for Sick Children, Toronto, ON, Canada, ${ }^{3}$ Division of Applied Molecular Oncology, Ontario Cancer Institute, the University Health Network, Toronto, M5G 2M9 Canada and 4Department of Pathology and Molecular Medicine, Richardson Labs, Queen's University, Kingston, K7L 3N6 Canada

Received: 29 October 2009 Accepted: 13 May 2010

Published: 13 May 2010

\section{References}

1. Sakamoto A, Iwamoto Y: Current status and perspectives regarding the treatment of osteo-sarcoma: chemotherapy. Rev Recent Clin Trials 2008, 3(3):228-231.

2. Gorlick R: Osteosarcoma: clinical practice and the expanding role of biology. Journal of musculoskeletal \& neuronal interactions 2002, 2(6):549-551

3. Batanian JR, Cavalli LR, Aldosari NM, Ma E, Sotelo-Avila C, Ramos MB, Rone JD, Thorpe CM, Haddad BR: Evaluation of paediatric osteosarcomas by classic cytogenetic and CGH analyses. Mol Pathol 2002, 55(6):389-393.

4. Lim G, Karaskova J, Beheshti B, Vukovic B, Bayani J, Selvarajah S, Watson SK, Lam WL, Zielenska M, Squire JA: An integrated mBAND and submegabase resolution tiling set (SMRT) CGH array analysis of focal amplification, microdeletions, and ladder structures consistent with breakage-fusion-bridge cycle events in osteosarcoma. Genes Chromosomes Cancer 2005, 42(4):392-403.

5. Lim G, Karaskova J, Vukovic B, Bayani J, Beheshti B, Bernardini M, Squire JA, Zielenska M: Combined spectral karyotyping, multicolor banding, and microarray comparative genomic hybridization analysis provides a detailed characterization of complex structural chromosomal rearrangements associated with gene amplification in the osteosarcoma cell line MG-63. Cancer Genet Cytogenet 2004, 153(2):158-164.

6. Sandberg AA, Bridge JA: Updates on the cytogenetics and molecular genetics of bone and soft tissue tumors: osteosarcoma and related tumors. Cancer Genet Cytogenet 2003, 145(1):1-30

7. Selvarajah S, Yoshimoto M, Maire G, Paderova J, Bayani J, Squire JA Zielenska M: Identification of cryptic microaberrations in osteosarcoma by high-definition oligonucleotide array comparative genomic hybridization. Cancer Genet Cytogenet 2007, 179(1):52-61.

8. Squire JA, Pei J, Marrano P, Beheshti B, Bayani J, Lim G, Moldovan L, Zielenska M: High-resolution mapping of amplifications and deletions in pediatric osteosarcoma by use of CGH analysis of CDNA microarrays. Genes Chromosomes Cancer 2003, 38(3):215-225.

9. Zielenska M, Marrano P, Thorner P, Pei J, Beheshti B, Ho M, Bayani J, Liu Y, Sun BC, Squire JA, et al: High-resolution CDNA microarray CGH mapping of genomic imbalances in osteosarcoma using formalin-fixed paraffinembedded tissue. Cytogenet Genome Res 2004, 107(1-2):77-82.

10. Tang N, Song WX, Luo J, Haydon RC, He TC: Osteosarcoma development and stem cell differentiation. Clinical orthopaedics and related research 2008, 466(9):2114-2130

11. Thomas D, Kansara M: Epigenetic modifications in osteogenic differentiation and transformation. J Cell Biochem 2006, 98(4):757-769.

12. Walkley CR, Qudsi R, Sankaran VG, Perry JA, Gostissa M, Roth SI, Rodda SJ, Snay E, Dunning P, Fahey FH, et al:: Conditional mouse osteosarcoma, dependent on $\mathrm{p} 53$ loss and potentiated by loss of $\mathrm{Rb}$, mimics the human disease. Genes Dev 2008, 22(12):1662-1676.

13. Gokgoz N, Wunder JS, Mousses S, Eskandarian S, Bell RS, Andrulis IL: Comparison of p53 mutations in patients with localized osteosarcoma and metastatic osteosarcoma. Cancer 2001, 92(8):2181-2189.

14. Miller CW, Aslo A, Tsay C, Slamon D, Ishizaki K, Toguchida J, Yamamuro T, Lampkin B, Koeffler HP: Frequency and structure of p53 rearrangements in human osteosarcoma. Cancer research 1990, 50(24):7950-7954.

15. Radig K, Schneider-Stock R, Oda Y, Neumann W, Mittler U, Roessner A: Mutation spectrum of $\mathrm{p} 53$ gene in highly malignant human osteosarcomas. Gen Diagn Pathol 1996, 142(1):25-32.

16. Fuchs B, Pritchard DJ: Etiology of osteosarcoma. Clinical orthopaedics and related research 2002, 397:40-52.

17. Deshpande A, Hinds PW: The retinoblastoma protein in osteoblast differentiation and osteosarcoma. Curr Mol Med 2006, 6(7):809-817.
18. Sadikovic B, Yoshimoto M, Al-Romaih K, Maire G, Zielenska M, Squire JA: In vitro analysis of integrated global high-resolution DNA methylation profiling with genomic imbalance and gene expression in osteosarcoma. PLOS ONE 2008, 3(7):e2834.

19. Sadikovic B, Yoshimoto M, Chilton-MacNeill S, Thorner P, Squire JA, Zielenska M: Identification of interactive networks of gene expression associated with osteosarcoma oncogenesis by integrated molecular profiling. Hum Mol Genet 2009, 18(11):1962-1975.

20. Gamberi G, Benassi MS, Bohling T, Ragazzini P, Molendini L, Sollazzo MR, Pompetti F, Merli M, Magagnoli G, Balladelli A, et al:: C-myc and c-fos in human osteosarcoma: prognostic value of mRNA and protein expression. Oncology 1998, 55(6):556-563.

21. Wu JX, Carpenter PM, Gresens C, Keh R, Niman H, Morris JW, Mercola D: The proto-oncogene c-fos is over-expressed in the majority of human osteosarcomas. Oncogene 1990, 5(7):989-1000.

22. Lu XY, Lu Y, Zhao YJ, Jaeweon K, Kang J, Xiao-Nan L, Ge G, Meyer R, Perlaky $L$, Hicks J, et al:: Cell cycle regulator gene CDC5L, a potential target for 6p12-p21 amplicon in osteosarcoma. Mol Cancer Res 2008, 6(6):937-946.

23. Maire G, Yoshimoto M, Chilton-MacNeill S, Thorner PS, Zielenska M, Squire JA: Recurrent RECQL4 imbalance and increased gene expression levels are associated with structural chromosomal instability in sporadic osteosarcoma. Neoplasia 2009, 11(3):260-268. 263p following 268

24. Davicioni E, Wai DH, Anderson MJ: Diagnostic and prognostic sarcoma signatures. Molecular Diagnosis and Therapy 2008, 12(6):359-374.

25. Cervigne NK, Reis PP, Machado J, Sadikovic B, Bradley G, Galloni NN, Pintilie M, Jurisica I, Gilbert R, Gullane P, et al:: Identification of a microRNA signature associated with progression of leukoplakia to oral carcinoma. Human Molecular Genetics 2009.

26. Parsons DW, Jones $S$, Zhang X, Lin JC, Leary RJ, Angenendt P, Mankoo P, Carter H, Siu IM, Gallia GL, et al:: An integrated genomic analysis of human glioblastoma multiforme. Science 2008, 321(5897):1807-1812.

27. McLendon R, Friedman A, Bigner D, Van Meir EG, Brat DJ, Mastrogianakis M, Olson JJ, Mikkelsen T, Lehman N, Aldape K, et al.: Comprehensive genomic characterization defines human glioblastoma genes and core pathways. Nature 2008.

28. Rogers S, Cambrosio A: Making a new technology work: the standardization and regulation of microarrays. Yale Journal of Biology and Medicine 2007, 80(4):165-178.

29. Farragher SM, Tanney A, Kennedy RD, Paul Harkin D: RNA expression analysis from formalin fixed paraffin embedded tissues. Histochemistry and Cell Biology 2008, 130(3):435-445.

30. Li G, Zhang W, Zeng H, Chen L, Wang W, Liu J, Zhang Z, Cai Z: An integrative multi-platform analysis for discovering biomarkers of osteosarcoma. BMC Cancer 2009, 9:150.

31. Kresse SH, Ohnstad HO, Paulsen EB, Bjerkehagen B, Szuhai K, Serra M, Schaefer KL, Myklebost O, Meza-Zepeda LA: LSAMP, a novel candidate tumor suppressor gene in human osteosarcomas, identified by array comparative genomic hybridization. Genes, Chromosomes and Cancer 2009, 48(8):679-693.

32. Rosen G, Caparros B, Huvos AG, Kosloff C, Nirenberg A, Cacavio A, Marcove RC, Lane JM, Mehta B, Urban C: Preoperative chemotherapy for osteogenic sarcoma: selection of postoperative adjuvant chemotherapy based on the response of the primary tumor to preoperative chemotherapy. Cancer 1982, 49(6):1221-1230.

33. Picci P, Sangiorgi L, Rougraff BT, Neff JR, Casadei R, Campanacci M: Relationship of chemotherapy-induced necrosis and surgical margins to local recurrence in osteosarcoma. $J$ Clin Oncol 1994, 12(12):2699-2705

34. Fritsch MK, Bridge JA, Schuster AE, Perlman EJ, Argani P: Performance characteristics of a reverse transcriptase-polymerase chain reaction assay for the detection of tumor-specific fusion transcripts from archival tissue. Pediatr Dev Pathol 2003, 6(1):43-53.

35. Livak KJ, Schmittgen TD: Analysis of relative gene expression data using real-time quantitative PCR and the 2(-Delta Delta $C(T)$ ) Method. Methods 2001, 25(4):402-408.

36. Bender R, Lange S: Adjusting for multiple testing--when and how? Journal of clinical epidemiology 2001, 54(4):343-349.

37. Sadikovic B, Al-Romaih K, Squire JA, Zielenska M: Cause and consequences of genetic and epigenetic alterations in human cancer. Curr Genomics 2008, 9(6):394-408.

38. el-Deiry WS, Harper JW, O'Connor PM, Velculescu VE, Canman CE, Jackman J, Pietenpol JA, Burrell M, Hill DE, Wang Y, et al.: WAF1/CIP1 is 
induced in p53-mediated G1 arrest and apoptosis. Cancer research 1994, 54(5):1169-1174.

39. Brazier H, Stephens S, Ory S, Fort P, Morrison N, Blangy A: Expression profile of RhoGTPases and RhoGEFs during RANKL-stimulated osteoclastogenesis: identification of essential genes in osteoclasts. $J$ Bone Miner Res 2006, 21(9):1387-1398.

40. Carlo-Stella C, Lavazza C, Locatelli A, Vigano L, Gianni AM, Gianni L: Targeting TRAIL agonistic receptors for cancer therapy. Clin Cancer Res 2007, 13(8):2313-2317.

41. Lian JB, Javed A, Zaidi SK, Lengner C, Montecino M, van Wijnen AJ, Stein $J L$, Stein GS: Regulatory controls for osteoblast growth and differentiation: role of Runx/Cbfa/AML factors. Critical Reviews in Eukaryotic Gene Expression 2004, 14(1-2):1-41.

42. Zhang HY, Jin L, Stilling GA, Ruebel KH, Coonse K, Tanizaki Y, Raz A, Lloyd RV: RUNX1 and RUNX2 upregulate Galectin-3 expression in human pituitary tumors. Endocrine 2009, 35(1):101-111.

43. Nakahara S, Oka N, Raz A: On the role of galectin-3 in cancer apoptosis. Apoptosis 2005, 10(2):267-275.

44. Khanna C, Khan J, Nguyen P, Prehn J, Caylor J, Yeung C, Trepel J, Meltzer P, Helman L: Metastasis-associated differences in gene expression in a murine model of osteosarcoma. Cancer research 2001, 61(9):3750-3759.

45. Vladimirova V, Waha A, Luckerath K, Pesheva P, Probstmeier R: Runx2 is expressed in human glioma cells and mediates the expression of galectin-3. Journal of Neuroscience Research 2008, 86(11):2450-2461

46. Blyth K, Vaillant F, Hanlon L, Mackay N, Bell M, Jenkins A, Neil JC, Cameron ER: Runx2 and MYC collaborate in lymphoma development by suppressing apoptotic and growth arrest pathways in vivo. Cancer research 2006, 66(4):2195-2201.

47. Pregizer S, Baniwal SK, Yan X, Borok Z, Frenkel B: Progressive recruitment of Runx2 to genomic targets despite decreasing expression during osteoblast differentiation. Journal of Cellular Biochemistry 2008, 105(4):965-970

48. Maruyama Z, Yoshida CA, Furuichi T, Amizuka N, Ito M, Fukuyama R, Miyazaki T, Kitaura H, Nakamura K, Fujita T, et al: Runx2 determines bone maturity and turnover rate in postnatal bone development and is involved in bone loss in estrogen deficiency. Developmental Dynamics 2007, 236(7):1876-1890

49. Pratap J, Wixted JJ, Gaur T, Zaidi SK, Dobson J, Gokul KD, Hussain S, van Wijnen AJ, Stein JL, Stein GS, et al.: Runx2 transcriptional activation of Indian Hedgehog and a downstream bone metastatic pathway in breast cancer cells. Cancer research 2008, 68(19):7795-7802.

50. Dalla-Torre CA, Yoshimoto M, Lee CH, Joshua AM, de Toledo SR, Petrilli AS, Andrade JA, Chilton-MacNeill S, Zielenska M, Squire JA: Effects of THBS3, SPARC and SPP1 expression on biological behavior and survival in patients with osteosarcoma. BMC Cancer 2006, 6:237.

51. Luo X, Chen J, Song WX, Tang N, Luo J, Deng ZL, Sharff KA, He G, Bi Y, He $B C$, et al:: Osteogenic BMPs promote tumor growth of human osteosarcomas that harbor differentiation defects. Lab Invest 2008, 88(12):1264-1277

52. Lamour V, Detry C, Sanchez C, Henrotin Y, Castronovo V, Bellahcene A: Runx2- and histone deacetylase 3-mediated repression is relieved in differentiating human osteoblast cells to allow high bone sialoprotein expression. J Biol Chem 2007, 282(50):36240-36249.

53. Cleton-Jansen AM, Anninga JK, Briaire-de Bruijn IH, Romeo S, Oosting J, Egeler RM, Gelderblom H, Taminiau AH, Hogendoorn PC: Profiling of high-grade central osteosarcoma and its putative progenitor cells identifies tumourigenic pathways. British journal of cancer 2009, 101(12):2064

54. Berger M, Muraro M, Fagioli F, Ferrari S: Osteosarcoma derived from donor stem cells carrying the Norrie's disease gene. N Engl J Med 2008, 359(23):2502-2504.

55. Tolar J, Nauta AJ, Osborn MJ, Panoskaltsis Mortari A, McElmurry RT, Bell S, Xia L, Zhou N, Riddle M, Schroeder TM, et al: Sarcoma derived from cultured mesenchymal stem cells. Stem Cells 2007, 25(2):371-379.

Pre-publication history

The pre-publication history for this paper can be accessed here:

http://www.biomedcentral.com/1471-2407/10/202/prepub doi: 10.1186/1471-2407-10-202

Cite this article as: Sadikovic et al., Expression analysis of genes associated with human osteosarcoma tumors shows correlation of RUNX2 overexpression with poor response to chemotherapy BMC Cancer 2010, 10:202

\section{Submit your next manuscript to BioMed Central and take full advantage of:}

- Convenient online submission

- Thorough peer review

- No space constraints or color figure charges

- Immediate publication on acceptance

- Inclusion in PubMed, CAS, Scopus and Google Scholar

- Research which is freely available for redistribution

Submit your manuscript at www.biomedcentral.com/submit
C Biomed Central 